\title{
BILATERAL HEARING LOSS AFTER SPINAL ANAESTHESIA
}

\author{
Ahmed $\mathrm{M}^{1}$, Chowdhury MRA ${ }^{2}$, Islam $\mathrm{MS}^{3}$, Ahmmed $\mathrm{S}^{4}$
}

\begin{abstract}
Introduction
Mild and transient hearing deficiency is not very uncommon after anaesthesia which improves before patient is fully aware of the problem. But complete prolong bilateral hearing loss after spinal anaesthesia is extremely rare complication, which falls in the category of sudden sensorineural hearing loss (SSNHL). The diagnosis and management of SSNHL is still controversial. Amongst several definition most acceptable criteria for SSNHL given by Wilson et $\mathrm{al}^{1}$.

i,e, $30 \mathrm{db}$ sensorineural loss

in $>3$ contiguous frequencies

in $<3$ days

Most common causes are

a. Viral or other infection (syphillis, encephalitis).

b. Vascular- occlusion, thrombosis, haemorrhage, spasm

c. Autoimmune

d. Hypoxia

e. Barotrauma, ototoxic drug, multiple sclerosis

f. Haematological- hyperviscosity syndrome, sickle cell disease

g. Meniere's disease

h. Vestibular schwannoma
\end{abstract}

\section{Case Report}

An elderly male, aged 55 years reported to outpatient clinic of anaesthesiology department, Combined Military Hospital (CMH) Dhaka for preanaesthetic checkup. The patient was a diagnosed case of benign enlargement of prostate and ischaemic heart disease, scheduled for transurethral resection of prostate (TURP). He had no other systemic disease like diabetes mellitus, hypertension, bronchial asthma or hypersensitivity to any drug. Routine investigations like blood complete picture, fasting blood sugar, urea, serum creatinine, electrolytes, liver function test, coagulation profile, hepatitis viral profile (as patient had a history of viral hepatitis 20 years back), chest X-ray were within normal limit. ECG revealed $\mathrm{T}$ depression in $\mathrm{L}, \mathrm{avL}, \mathrm{V}$ and echocardiography shows- posterior wall akinesia with fair LV function (EF$50 \%$ ). The patient was receiving once daily doses of tablets aspirin $75 \mathrm{mg}$, atorvastine $10 \mathrm{mg}$ and atenolol $25 \mathrm{mg}$ and twice daily doses of tablets mononitrate $10 \mathrm{mg}$ and omeprazole $20 \mathrm{mg}$.

Considering his history, clinical examination and investigation reports patient was accepted in ASA Grade-II and Mallampati class I. He was advised to remain nothing per oral (NPO) for 06 hours before operation and to take tablets diazepum $05 \mathrm{mg}$ at bed time and monocard and atenolol in usual dose.

Next day patient underwent TURP under subarachnoid block. After routine preloading $(15 \mathrm{ml} / \mathrm{kg}$ of Hartmann's solution IV), $12.5 \mathrm{mg}$ of injection heavy bupivacaine injected into his subarachnoid space between 3rd and 4th lumbar vertebral level by 25 gauze Quincke type of spinal needle in single prick in sitting position. He was given $\mathrm{O}_{2}$ $3 \mathrm{~L} / \mathrm{min}$ by face mask. All through the operative procedure patient was haemodynamically stable and all other basal parameters were within normal limit and there was no complaints from patient, surgery itself was smooth and completed within 25 minutes.

Operation night was uneventful. But on next day early morning patient complained of severe headache, tinnitus and almost complete loss of hearing power in both ear. Headache was typical of post dural puncture headache (PDPH). But such sudden bilateral complete hearing loss was unprecedented. Treatment started in line of PDPH and SSNHL along with otolaryngologist and urologist. Thorough history, clinical examination and investigations were carried out to exclude all the probable causes of SSNHL and evaluate the present auditory status. Patient had no history of any auditory problem or any systemic disease which can contribute to develope such crisis. Additional investigations like TSH, VDRL and MRI of brain were within normal limits. Audiogram and tympanogram were consistent with SSNHL and it was $>80 \%$ (bilateral).

The patient was kept restricted in bed in supine position. He was kept hydrated with plenty of oral and intravenous fluid. The patent received once daily dose of intravenous Ceftriaxon $1 \mathrm{mg}$, twice daily doses of tablets midazolam $7.5 \mathrm{mg}$, prochlorperazine, almitrine+raubasine(Duxil), vinpocetine (Cavinton) and capsule omeprazole $20 \mathrm{mg}$ and thrice daily dose of tablet prednisolone.

PDPH reduced on the next day but deafness persisted and shown improvement from 3rd day and within a week patient completely recovered his hearing power. Otherwise the post operative period was uneventful. As such patient was discharged after one week with advice to follow up for next six month in both urology and ENT department. Patient became asymptomatic regarding auditory function.

1. Maj Masud Ahmed MBBS, FCPS, Anaesthesiology, CMH Dhaka, 2. Brig Gen Md. Rezaul Alam Chowdhury. MBBS, MD, Anaesthesiology, CMH Dhaka, 3. Lt Col Md. Shahidul Islam. MBBS, MCPS, FCPS (Gen Surgery), FCPS(Urology), Urology, CMH Dhaka, 4. Maj Salahuddin Ahmmed. MBBS, DLO, MCPS, ENT, CMH Dhaka.

JAFMC Bangladesh. Vol 5, No1 (June) 2009 

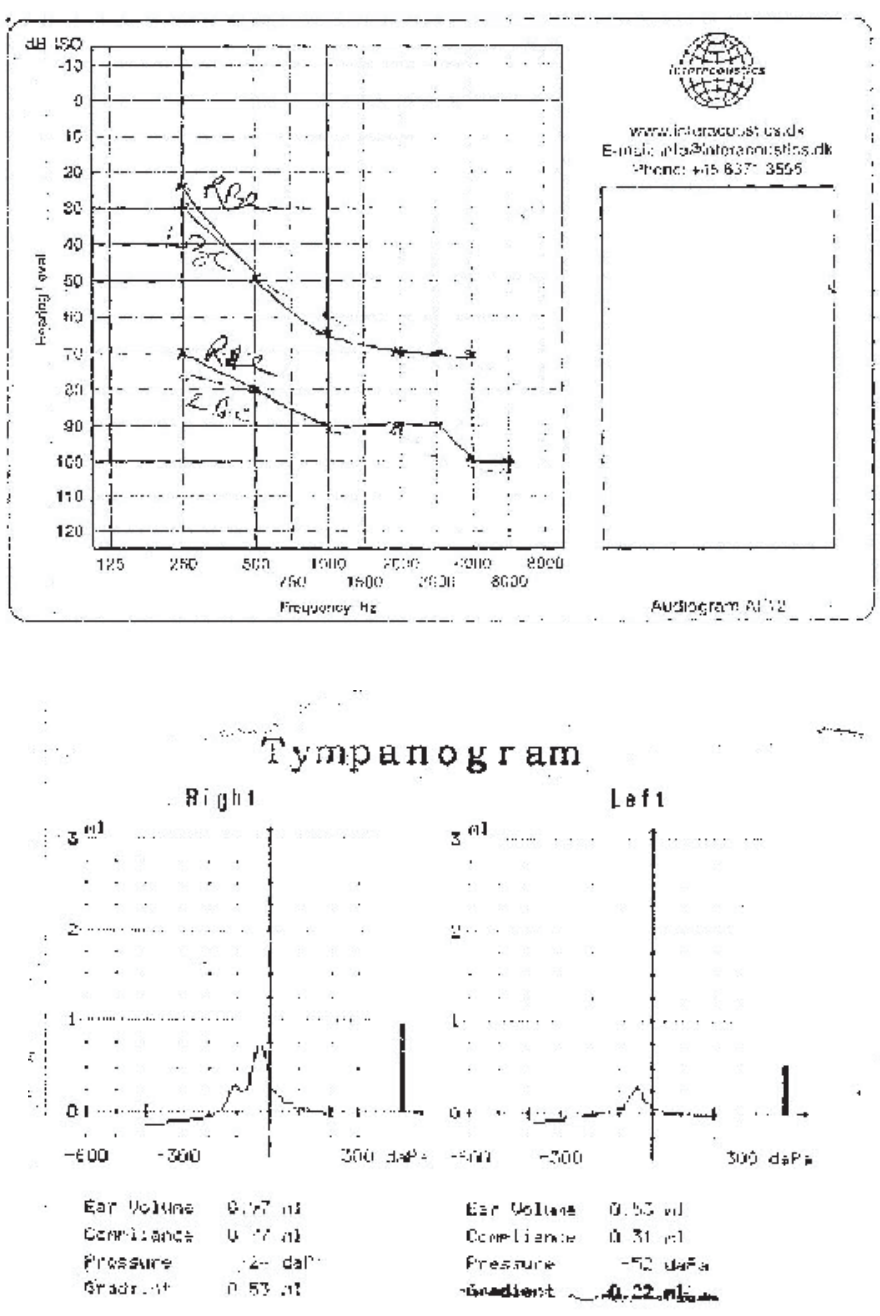

Ref 1 ex
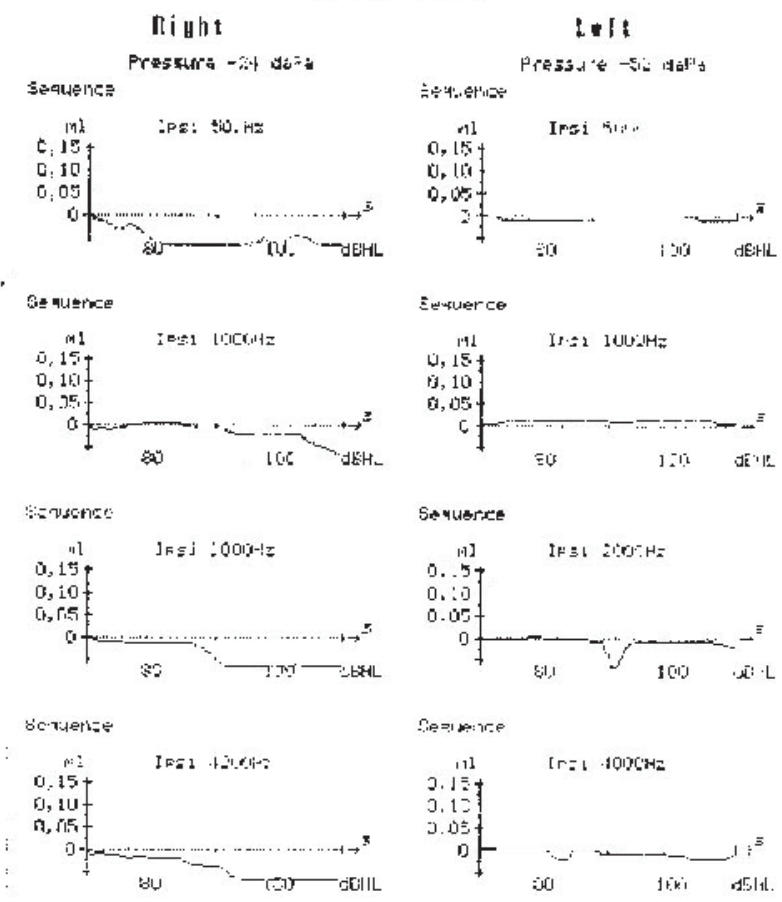

\section{Discussion}

Sudden sensorineural hearing loss (SSNHL) after subarachnoid block is a very rare complication and little difficult to explain. The Cerebro-spinal Fluid (CSF) dynamics are important for auditory function of the inner ear. The structures of the inner ear are embedded in the labyrinth of the temporal bone and consist of separate receptor mechanism, the vestibule and semicircular canals (vestibular end organ) and cochlea (acoustic end organ). Both the round and the oval window open to the inner ear from the middle ear. The membranous labyrinth encloses endolymph that fills a hollow system within, the inner ear. Perilymph a filtrate of blood and CSF is the substrate for the inner ear cells and present in the cochlea. There is a passive diffusion as well as active transport of ions between endolymph and perilymph. The mechanism of hearing loss after spinal anaesthesia is attributed to the disruption of this endolymph/perilymph balance caused by the decreased CSF pressure due to leakage of CSF through the dural puncture site. In most individuals the movement of fluid between the endolymph and the perilymph is small and well compensated ${ }^{2}$. Michel and Brains ${ }^{3}$ have suggested the mechanism of transient hearing loss after Sub-arachnoid Block $(\mathrm{SAB})$ relates to aberrancy of the anatomy of the cochlear aqueduct leading to the decreased flow of CSF through it, which occurs in approximately 2 in 1000 patients. The increase flow in the aqueduct decreases the perilymphatic pressure when CSF pressure decreases after a dural puncture. This decreases in perilymphatic pressure leads to an increase in the endolymphatic pressure resulting in the formation of endolymphatic hydrops, which displaces the hair cells on the basement membrane and results in low frequency hearing loss ${ }^{3}$.

It is interesting to note that loss of hearing for higher frequencies is more common in elderly male ${ }^{4}$. It is possible that older patients may be more susceptible to the effects of subtle changes in inner ear pressure imbalance caused by CSF leakage. Fog et $\mathrm{al}^{5}$ have reported a $92 \%$ of incidence of a decrease in hearing level of $>10 \mathrm{~dB}$ with a $22 \mathrm{G}$ spinal needle and a $29 \%$ incidence with a $26 \mathrm{G}$ needle in patients undergoing TURP which is transient and negligible.

Multiple studies have described a variable incidence of transient hearing loss (hypoacusis) from $0.4 \%$ to $40 \%$ after SAB especially in low frequency range ${ }^{6,7}$ But these were not significant and does not fulfill the criteria of SSNHL. The type of the tip and size of the spinal needle influence hearing loss as it does in $\mathrm{PDPH}^{8,9}$. Helene Finegold et al showed ${ }^{10}$ that $\mathrm{SAB}$ in obstetric population did not cause SSNHL even after using different sizes of needles with different type of tips. Several authors have suggested an association between PDPH and hearing loss ${ }^{3}$, whereas others found hearing loss without associated headache ${ }^{7}$.

Fig - 1: Audiogram \& Tympanogram of the patient. 
Epidural anaesthesia may also cause a brief period of hearing loss $(<10 \mathrm{~min})$ because the transient increase in CSF pressure caused by injection of fluid into the epidural space may affect the function of the cochlear cells $^{6}$. There are no reports of long term hearing dificits after uneventful lumbar epidural anaesthesia. Postoperative hearing loss following general anaesthesia is also very rare $(5-20: 100,000)$ and has mostly been reported in patients following cardiopulmonary bypass (CPB). This is thought to be the result of microemboli, calcium, fat and particulate matter deposition ${ }^{11}$.

Hypoperfusion causing infarction to the basilar circulation during the time of extracorporeal circulation is also thought to be the result of CSF loss and hence an intracranial pressure drop creating a pressure imbalance ${ }^{12}$. The Abducens, Facial and the Vestibulocochlear nerves are predominantly affected.

The management of SSNHL following surgery is inconclusive. Maintaining CSF pressure and vasodialatation thereby adequate oxygenation of hair cells is basic of all management of SSNHL. So treatment relies on the traditional management of PDPH and some adjuvant drugs or procedures to ensure adequate oxygenation. Even some patients get cured without any treatment or only with placebo.

Results of the use of steroids (prednisolone, betamethasone), antiviral agents (interferon, acyclovir), IV fluid (dextran, HES), vasodialators (prostacycline, verapamil, nifedipine), sedatives, vitamins and antioxydants (high dose vitamin $\mathrm{B}_{1,6,12}, \mathrm{C}, \mathrm{A}$ and $\mathrm{E}$ ), neurooxygenator (vinpocetine, almitrine+raubasine, carbogen$\mathrm{CO}_{2}+\mathrm{O}_{2}$ ) have been variable ${ }^{13}$. The value of steroids in the treatment of idiopathic SSNHL remains unclear although routinely used in modern practice.

A recent study reported a higher incidence of success in cervicothoracic epidural compared to stellate ganglion block. A higher blood flow to the cochlear region may be the main mechanism ${ }^{14}$.

Bennett and colleagues reviewed the use of hyperbaric oxygen therapy (HBOT) in SSNHL and tinnitus in 2005 but not advocated for its routine use as its role was not significant ${ }^{15}$. Even after most acceptable modern regime can't guarantee full cure and symptom may persist for years. The risk factors leading to poor prognosis include initial severity, timing of intervention and treatment, vestibular symptoms and the affected range of audiographic frequencies ${ }^{16}$. As it a very rare complication of $\mathrm{SAB}$, it is still not recommended to inform the patient preoperativey regarding the potential risk of hearing loss after regional anaesthesia ${ }^{10}$.

\section{Conclusion}

Unexpected complication during postoperative period is puzzling experience of anaesthetist. Regarding management the key is not to be panic. Assurance of the patient and exclusion of all probable causes along with team effort can overcome such unexpected complication of routine anaesthetic procedure. Better understanding of this mysterious condition is crucial to improve safety profile.

\section{References}

1. Wilson WR, Byl FM, Laird N. The efficiency of steroids in the treatment of idiopathic sudden hearing loss. A double blind clinical study. Archieves of Otolaryngology 1980; 106 : 772-6.

2. Becker WB, Nauman HH, P Faltz, CR. Ear nose and throat disease; a pocket reference. New York: Thieme Medical Publishers; 1989.

3. Michel O, Brusis T. Hearing loss as a sequel of lumbar puncture Ann Otol Rhinol Laryngol 1992; $101: 390-4$.

4. Abrass IB. Biology of aging In: Harrison's principles of internal Medicine. 12th ed. New York : McGraw Hill 1991 .p. 67.

5. Fog J. Wand Lp. Sundberg A, et al. Hearing loss after spinal anaesthesia is related to needle size. Anaesthesia Analog 1990; 70: 517-22 6. Day CJE, Smith LE. Auditory ocular and facial complications of central neural block; a review of possible mechanisms. Reg Anesth 1996; $21: 197-201$.

7. Wang LP, Lamdberg J. MagnuSson M. et al. Auditory function after spinal anaesthesia. Reg Anesth 1993; $18: 162-5$.

8. Sundberg A. Wang LP, Fog J. Influence on hearing of $22 \mathrm{G}$ Whitacre and 22G Quincke needle .Anaesthesia 1992; 47 : 981-3

9. Fog J. Wang LP, Sundberg A, et al. Hearing loss after spinal anaesthesia is related to needle size. Anesth Analog 1990; $70: 517-22$

10. Finegold HD, Mandell G, Vallejo M, Ramanathan S. Does spinal anaesthesia cause hearing loss in the obstetric population? Anesth Analg 2002; $95: 198-203$

11. Walsted A, Anderson UK, Berthelsem PG, Olesen A. Hearing loss after cardiopulmonary bypass surgery.Eur Arch Otorhinolaryngol 2000; 257:124-7.

12. Wang LP. Sudden bilateral hearing loss after spinal anaesthesia. A case report. Acta Anaesthesiol Scand 1986;30:412-3.

13. Eisenman OJ, Arts HA. Effectiveness of treatment for sudden sensorineural hearing loss. Arch Otolaryngol. Head Neck Surg 2000; $126: 1161-4$.

14. Fujino M, Hisashi K, Yashima N, et al. Treatment of sudden sensorineural hearing loss with a continuous epidural block. Eur Arch Otorhinolaryngol 1999; 256(supp) : s 18-21.

15. Bennett M Kertesz. T Young E .Hyperbaric oxygen therapy for idiopathic sudden sensorineural hearing loss and Tinnitus. A systematic review of randomised controlled trial. Journal of Laryngology and Otology 2005; $119: 791-8$.

16. Ito S. Fuse T, Yokota M ,et al. Prognosis is predicted by early hearing improvement in patients with idiopathic sudden sensorineural hearing loss. Clin Otolaryngol 2002; 27 : 501-4. 